\title{
Fuzzy TOPSIS Approach in Selection of Optimal Noise Barrier for Traffic Noise Abatement
}

\author{
Naveen GARG ${ }^{(1),(3)}, \operatorname{VISHESH}^{(2)}$, Sagar MAJI ${ }^{(3)}$ \\ (1) CSIR-National Physical Laboratory \\ New Delhi - 110012, India; e-mail: ngarg@nplindia.org \\ (2) Amity School of Engg. and Technology \\ Bijwasan, Delhi - 110 061, India \\ (3) Department of Mechanical Production and Industrial Engineering \\ Delhi Technological University \\ Delhi - 110042, India \\ (received February 13, 2015; accepted August 5, 2015)
}

\begin{abstract}
The paper presents a retrospective study for selection of noise barrier for road traffic noise abatement. The work proposes the application of Fuzzy TOPSIS (Technique for order preference by similarity to an ideal solution) approach is selection of optimal road traffic noise barrier. The present work utilizes the fuzzy TOPSIS model proposed by MAHDAVI et al. (2008) in determination of ranking order of various types of noise barriers with respect to the various criteria considered. It is suggested that application of this approach can be very helpful in selection and application of optimal noise barrier for road traffic noise abatement.
\end{abstract}

Keywords: fuzzy TOPSIS, MADM, road traffic noise, fuzzy positive ideal solution (FPIS), fuzzy negative ideal solution (FNIS), SWOT analysis.

\section{Introduction}

Noise barriers are designed to block the sound waves in the propagation path from source to receiver. The proximity to the source or receiver is the pivotal factor affecting the insertion loss provided by the barrier. The best solutions are probably when there is neither any control at the source, nor at the receiver (GARG et al., 2012a; 2013b). The diffraction edge behaves like a virtual source to the diffracted sound field. For a traditional straight edge barrier, the phase of the source along the edge is coherent. The phase will be random and less coherent when a random edge profile is present on the barrier (SHAO et al., 2001). ShaO et al. (2001) and Ho et al. (1997) proposed noise barriers with random edge profiles to decrease the coherence in the diffracted sources. Thus, the addition of multiple edges to a simple plain barrier provides added insertion loss without increasing its height. These new profiles are generally placed on the top of conventional barriers to enhance their diffrac- tion efficiency and to reduce the sound diffracted into the shadow zone (WATTs et al., 2004). These combined versions, usually called multiple edge barriers, are very useful for screening transportation noise in situations where the maximum height of noise barriers needs to be limited due to environmental considerations like visual intrusion, reduction in sunlight, etc., and where extra screening is required in existing structures with minimum resources (WATTS, 2002).

Improving the acoustic performance of a vertical barrier without increasing its height is a challenge to the acoustic engineer. The conventional barriers used are generally the concrete or masonry walls, transparent barriers, etc, while the innovative designs include mainly diffracting - edge modifications in the form of additional fixtures or tops. The major innovative diffraction-edge modifications include T-shaped barriers, multiple-edge barriers, and Y-shaped barriers (EGAN et al., 2006). Multiple edge barriers give consistent improvements in insertion loss over a wide area as compared with plane reflective barriers. Also 
the benefits from these profiles occur throughout the sound spectrum even at low frequencies. Many of these systems incorporate absorption surfaces, resonant cavities to produce soft surfaces, provisions to promote destructive interferences, etc.

A wide range of barrier systems have been identified in literature. These can be conveniently divided into two distinct groups, viz. a single barrier of different shapes and multiple-edge barriers. Single shape noise barriers include wedge-shaped barriers, berms of different kinds, T-shaped and Y-shaped barriers, and arrow-profiled barriers. Multiple-edge barriers consist of two distinct categories, viz. multiple-edge barriers with a single foundation and those comprised of several parallel barriers on the same side of the road (DAIGLE, 1999).

WATts (2002) has classified barriers that may offer improved performance over simple plane barriers as i) absorptive barriers, ii) angled barriers, and iii) capped barriers. The absorptive barriers incorporate absorption elements on the traffic face that absorb a significant portion of the incident sound. The angled barriers have contoured surfaces angled to disperse the noise so as to prevent sound reflections into the shadow zone. The capped barriers have specially shaped top sections that reduce the sound power contribution from acoustic waves diffracted over the top (WATTS, 2002). The notable developments include parallel noise barriers (WATts, 1996), inclined barriers (Cheng, NG, 2001), barriers with absorbent/soft/reactive surfaces (FAHY et al., 1995; MonAZZAM et al., 2010; 2011), diffusive noise barriers (CIANFRINI et al., 2007), wedge shaped noise barriers (OUIs et al., 2003), multiple-edge noise barriers (CROMBIE et al., 1995), T-shaped noise barriers (BAULAC et al., 2008), and other novel barrier profiles (MAY et al., 1980) etc. The above studies generally include experimental, theoretical, and numerical analyses with an objective of predicting the barrier insertion loss in laboratory and free field conditions.

The addition of a horizontal cap to a conventional barrier thus creating a T-profile has been discussed in various studies and in most conditions; it has been observed that Y- and arrow profiles perform less efficiently than the T-profile barrier (HoTHERSALL et al., 1991). Design considerations for erection of noise barriers of optimum dimensions providing a high insertion loss are essential and depend upon site and situation. Barrier thickness is insignificant, but diffraction over the top edge of a barrier is affected by its cross section. Transparent barriers, tilted, dispersive barriers, and multiple edge design barriers prove to be fruitful options for road traffic noise abatement. The use of sound absorbing materials can definitely improve the performance of both single and parallel noise barriers. The Transport Research Laboratory, UK (WATTs, 1996) studies on full scale models had shown that the screening performance of a single barrier of $2 \mathrm{~m}$ height on the near side of a carriageway is reduced by $4 \mathrm{~dB}(\mathrm{~A})$ when a reflective barrier of a similar height is erected at the edge of the farside carriageway. Both sound absorptive and tilted barriers were found to be effective in reducing the degradation in single barrier performance. Placing absorptive materials on a single barrier helps to reduce the diffracted sound into the shadow zone and minimize the reverberant build up of noise between source and receiver. The barrier material must be more absorptive at frequencies that are significant in the source spectrum characteristics to be effective in noise abatement. The traffic noise barriers should absorb strongly over a wide range of frequencies between $250 \mathrm{~Hz}$ to $5 \mathrm{kHz}$. Superior modular sound absorbers developed by FAHY et al. (1995) can be either incorporated into a basic construction or quickly retrofitted into existing reflective barriers (FAHY et al., 1995). Full scale tests were conducted by WATts and Morgan (1996) to compare the efficiency of T-shape, multiple edges barriers, and double barriers. An improvement of 1 to $3 \mathrm{~dB}$ over simple plane reflective barriers of identical height was found. In a scale-model study involving thin, wide, T-shaped, cylindrically topped, corrugated, inclined, Y-shaped, arrow-profiled, etc., noise barriers and three highway situations, viz. a single barrier with a protected receiver, a single barrier with the receiver on the opposite side of the highway, and parallel barriers, one on each side of the highway, MAY and OSMAN (1980) had observed a higher noise reduction for T-profile (wide top) barriers and T-shape with absorptive top with cap widths of $0.6 \mathrm{~m}$ or more and of small cap thickness. Noise measurements with a $4 \mathrm{~m}$ highway noise barrier with a horizontal cap of $0.75 \mathrm{~m}$ (T-profile) in Toronto produced a noise reduction of 1-1.5 dB greater than that obtained for the same barrier without the cap (MAY, OsMAN, 1980). In a review of the barrier studies involving T-, Y-, and arrow profile noise barriers, numerical modelling and boundary element approach, Hothersall et al.(1991) had concluded that for barriers with reflecting surfaces, the changes in insertion losses for various profiles can be described by using the concept of path difference. Further the introduction of absorptive upper surfaces produces a significant increase in insertion loss. The experimental results of the performance of barriers having different shapes and surface conditions under well controlled environment showed that a soft $3 \mathrm{~m}$ high T-shaped barrier provided the same performance as a $10 \mathrm{~m}$ high plain barrier (ISHIZUKA, 2004). FUJIWARA et al. (1998) described the results of BEM modelling of a T-shaped barrier with a soft upper surface. A uniform level of wells in the upper surface of a T-shaped barriers produce insertion loss values equal to those of a soft surface over a significant range of frequencies.

A design morphology (Fig. 1) has been formulated from an exhaustive literature survey for sound barriers (Guidelines on design of noise barriers, Environmental 


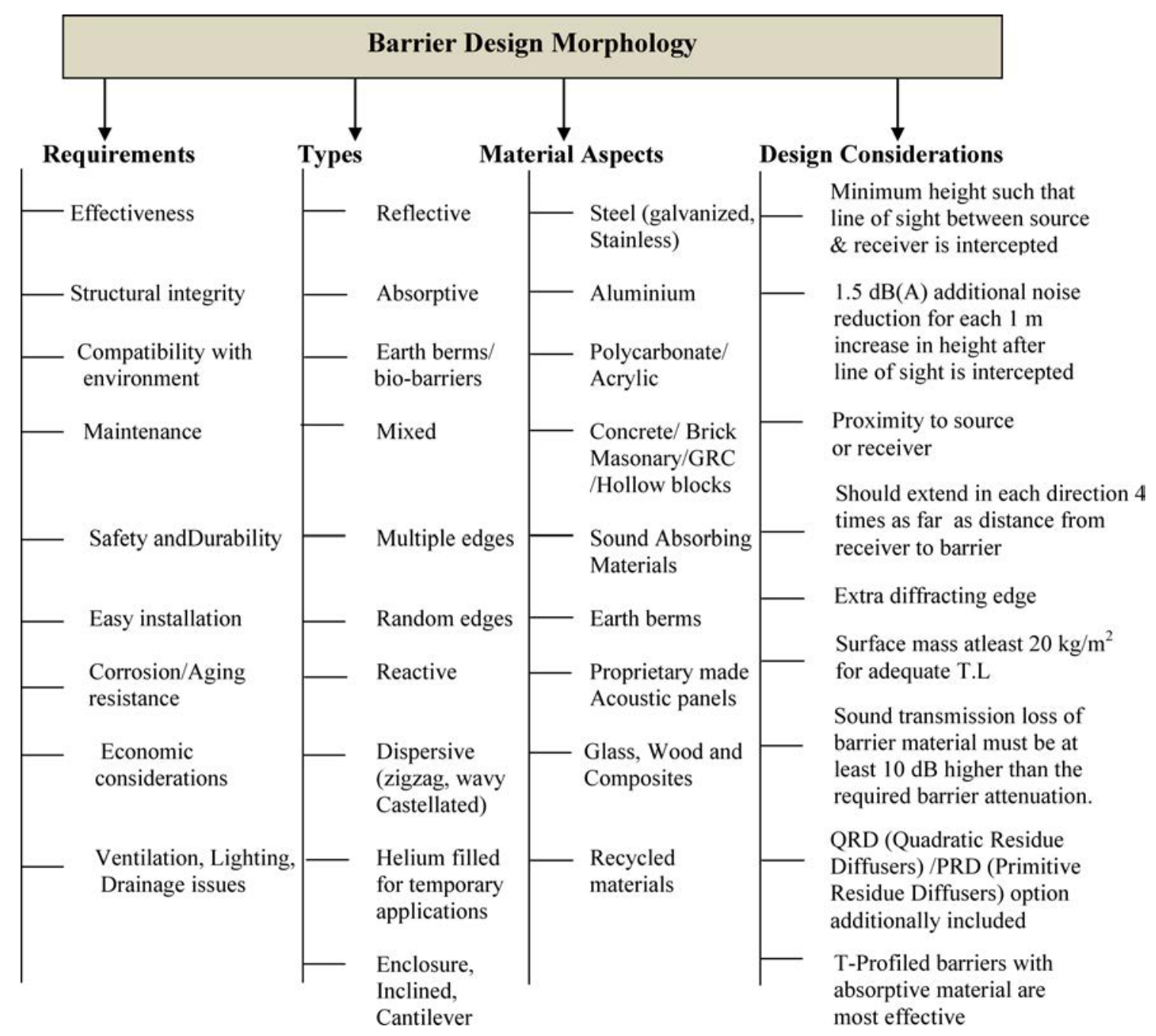

Fig. 1. Design morphology for noise barriers (GARG et al., 2012).

Protection Department, Govt of Hongkong, 2003; Federal Highway Administration Manual). The selection of a suitable barrier compatible for a particular road network depends upon acoustic attenuation (insertion loss); economical, structural, and aesthetic constraints, compatibility with environment, installation, maintenance and safety aspects, structural integrity, corrosion resistance, and factors like ventilation, lighting, drainage, vandalism, etc.

It is thus imperative for the town planners to consider all these criteria before finally selecting and installing the noise barrier for a particular site for noise abatement. There is no simple solution to such a problem wherein amongst the variable alternatives one has to find the optimal strategy considering the various benefit criteria. TOPSIS (Technique for Order Preference by Similarity to Ideal Solution) developed by HwANG and Yoon (1981) is one such probable solution to this problem. The present work illustrates a case study of application of the TOPSIS approach in selection of the optimal noise barrier for road traffic noise abatement using a fuzzy database of linguistic variables assigned by three experienced decision makers. Arizona Department of Transportation (ADOT) study (WATSON, 2006) on scoring the barrier options recommends the T-top design with absorptive materials over the conventional barrier of concrete or masonry construction. The present work extends these investigations inculcating the TOPSIS approach for formulating a Decision Matrix and finding the Best Practicable and Economical (BPEO) barrier option. It is envisaged that application of this approach can be instrumental in solving this problem with minimum numerical complexities and in minimum time.

\section{Methodology and application}

\subsection{TOPSIS method}

Amongst the various methods available for solution of Multiple Criteria Decision Making (MCDM) problems (VELASQUEZ et al. 2013), the Technique for order preference by similarity to an ideal solution (TOPSIS) approach is one of the most widely used. HwANG and 
YoON (1981) originally proposed TOPSIS to help select the best alternative with a finite number of criteria. The standard TOPSIS method attempts to choose alternatives that simultaneously have the shortest distance from the positive ideal solution and the farthest distance from the negative-ideal solution. The positive ideal solution maximizes the benefit criteria and minimizes the cost criteria, whereas the negative ideal solution maximizes the cost criteria and minimizes the benefit criteria (BEHZADIAN et al., 2012). BEHZADIAN et al. (2012) conducts a comprehensive literature review of applications of TOPSIS approach in various streams of science and engineering. They suggest a framework for future attempts in this area for academic researchers and practitioners. The advantages of TOPSIS include simple, rational, and comprehensible concept, good computational efficiency, ability to measure the relative performance for each alternative in a simple mathematical form (YeH, 2002; HUNG et al., 2009). The motivation is that the fuzzy TOPSIS method can take advantage of normalizing and defuzzifying fuzzy data collected from multiresponse quality problems and can utilize fuzzy entropy measures to provide objective weights for each criterion (RIBEIRO, 1996). The positive ideal solution is the one with the maximal benefit and minimal cost values among all possible alternatives. The negative ideal solution is the one with the minimal benefit and maximal cost values. The positive and negative ideal solutions can be found by way of weighting the normalized decision matrix. A relative closeness is computed and used for ranking of all possible alternatives by the measure of Euclidean distance from positive and negative ideal solution. The importance weights of various criteria and ratings of alternatives with regard to criteria are considered as linguistic variables. These variables are transformed into triangular fuzzy numbers. Final values of fuzzy numbers that contribute a fuzzy decision matrix and fuzzy weight vector are calculated as means of values assessed by the members of decision group. Normalization of decision matrix is performed and the fuzzy positive ideal solution (FPIS) and fuzzy negative ideal solution (FNIS) are determined. The distances of each alternative to FPIS and FNIS are calculated and corresponding closeness coefficient of each alternative to these solutions is evaluated. Thus, the alternatives are ranked based on the closeness coefficient (PRASCEVIC, 2013). The lower value of the closeness coefficient indicates that an alternative is close to FPIS and farthest from FNIS simultaneously (MAHDAVI et al., 2008). Thus, the alternatives are ranked according to the closeness coefficient in the ascending order. The procedure of application is relatively simple and easy to understand and apply, and as such it finds application in solving decision making problems in various fields. The merits of the integrated fuzzy TOPSIS is that not only the subjective and objective criteria are simultaneously considered in the real life, but also it releases the limitations of crisp values and facilitates its implementation as a computer based decision support system for ranking the alternatives in a fuzzy environment (DING, 2011). It is imperative to integrate fuzzy data in conjunction with linguistic variables for solution of such problems wherein the best alternative is to be selected with respect to various criteria under consideration.

\subsection{TOPSIS methodology}

Three experienced acousticians are chosen as decision makers for giving their inputs in terms of linguistic variables described in Tables 1 and 2 for ratings and importance weights of each criterion. Either actual values of the requirements against the various barrier alternatives or the use of linguistic variables correlated with fuzzy numbers to identify the ratings and weights could be the input in the decision making (Shahanaghi et al., 1999). It may be noted that the weight of a criterion is an important aspect and some authors suggest using the Analytical Hierarchical Process (AHP) or other techniques to obtain the weights, as in the study of SHIH et al. $(2001 ; 2007)$ and OlsON et al. (2004). However, in the present study, the topic of weight elicitation is not considered, as it is assumed that the weights of attributes or criteria are judiciously decided by the expert decision makers, D1, D2, and D3. The Strengths, Weaknesses, Opportunities, and Threats (SWOT) analysis is conducted for each of these alternatives (Table 3) for identifying

Table 1. Linguistic variables for the importance weight of each criterion (MAHDAVI et al., 2008).

\begin{tabular}{|c|c|c|}
\hline S. No. & Weight & Linguistic variables \\
\hline 1 & Very Low (VL) & $(0 ; 0 ; 0.1)$ \\
\hline 2 & Low (L) & $(0 ; 0.1 ; 0.3)$ \\
\hline 3 & Medium Low (ML) & $(0.1 ; 0.3 ; 0.5)$ \\
\hline 4 & Medium (M) & $(0.3 ; 0.5 ; 0.7)$ \\
\hline 5 & Medium High (MH) & $(0.5 ; 0.7 ; 0.9)$ \\
\hline 6 & High (H) & $(0.7 ; 0.9 ; 1.0)$ \\
\hline 7 & Very High (VH) & $(0.9 ; 1.0 ; 1.0)$ \\
\hline
\end{tabular}

Table 2. Linguistic variables for the ratings (MAHDAVI et al., 2008).

\begin{tabular}{|c|c|c|}
\hline S. No. & Ratings & Linguistic variables \\
\hline 1 & Very Poor (VP) & $(0 ; 0 ; 1)$ \\
\hline 2 & Poor $(\mathrm{P})$ & $(0 ; 1 ; 3)$ \\
\hline 3 & Medium Poor $(\mathrm{MP})$ & $(1 ; 3 ; 5)$ \\
\hline 4 & Fair $(\mathrm{F})$ & $(3 ; 5 ; 7)$ \\
\hline 5 & Medium Good $(\mathrm{MG})$ & $(5 ; 7 ; 9)$ \\
\hline 6 & Good $(\mathrm{G})$ & $(7 ; 9 ; 10)$ \\
\hline 7 & Very Good $(\mathrm{VG})$ & $(9 ; 10 ; 10)$ \\
\hline
\end{tabular}


Table 3. SWOT analysis of various available noise barrier options available.

\begin{tabular}{|c|c|c|c|c|}
\hline Barrier Type & Strengths & Weaknesses & Opportunities & Threats \\
\hline $\begin{array}{l}\text { T-Top barrier with ab- } \\
\text { sorptive top }\end{array}$ & $\begin{array}{l}\text { High insertion loss, } \\
\text { reduced barrier height } \\
\text { by } 1 \mathrm{~m} \text { on average }\end{array}$ & $\begin{array}{l}\text { Maintenance costs asso- } \\
\text { ciated with absorptive } \\
\text { material }\end{array}$ & $\begin{array}{l}\text { Instrumental for } \\
\text { specific source } \\
\text { screening }\end{array}$ & $\begin{array}{l}\text { Debris collection, } \\
\text { drainage issues, } \\
\text { vulnerable to ac- } \\
\text { cretion of particles } \\
\text { thrown by traffic } \\
\text { and of water and } \\
\text { ice due to natural } \\
\text { precipitation }\end{array}$ \\
\hline $\begin{array}{l}\text { Y-Top/Half Y with ab- } \\
\text { sorptive top }\end{array}$ & High insertion loss & $\begin{array}{l}\text { Wind loading, mainte- } \\
\text { nance issue }\end{array}$ & $\begin{array}{l}\text { Instrumental for } \\
\text { specific source } \\
\text { screening }\end{array}$ & $\begin{array}{l}\text { Debris collection, } \\
\text { drainage issues }\end{array}$ \\
\hline Jagged top & $\begin{array}{l}\text { Fair insertion loss, high } \\
\text { frequency mitigation }\end{array}$ & - & $\begin{array}{l}\text { Traffic noise abate- } \\
\text { ment }\end{array}$ & Structural integrity \\
\hline $\begin{array}{l}\text { Mushroom Top/Multi- } \\
\text { ple-edge top treat- } \\
\text { ment/Cylindrical top }\end{array}$ & High insertion loss & $\begin{array}{l}\text { Structural integrity, } \\
\text { debris associated with } \\
\text { use of absorptive mate- } \\
\text { rial }\end{array}$ & $\begin{array}{l}\text { Traffic noise abate- } \\
\text { ment, } \\
\text { specific source noise } \\
\text { screening }\end{array}$ & $\begin{array}{l}\text { Wind loading issue, } \\
\text { degradation and } \\
\text { maintenance asso- } \\
\text { ciated }\end{array}$ \\
\hline Transparent Barrier & $\begin{array}{l}\text { Fair insertion loss and } \\
\text { economical solution }\end{array}$ & $\begin{array}{l}\text { Noise reflecting } \\
\text { surface may add up } \\
\text { to cause a reverberant } \\
\text { noise field }\end{array}$ & $\begin{array}{l}\text { Traffic noise abate- } \\
\text { ment, } \\
\text { specific source noise } \\
\text { screening }\end{array}$ & Vandalism \\
\hline $\begin{array}{l}\text { Concrete Barrier/Hol- } \\
\text { low Concrete blocks }\end{array}$ & $\begin{array}{l}\text { High insertion loss, } \\
\text { minimal maintenance, } \\
\text { high structural inte- } \\
\text { grity, minimal mainte- } \\
\text { nance }\end{array}$ & $\begin{array}{l}\text { High costs and installa- } \\
\text { tion time }\end{array}$ & $\begin{array}{l}\text { Hollow blocks for } \\
\text { low frequency noise } \\
\text { control, absorptive } \\
\text { GRC barriers }\end{array}$ & $\begin{array}{l}\text { High costs of erec- } \\
\text { tion of barrier }\end{array}$ \\
\hline Reflective Barrier & Fair insertion loss & $\begin{array}{l}\text { Noise reflecting surface } \\
\text { may add up to cause a } \\
\text { reverberant noise field }\end{array}$ & $\begin{array}{l}\text { Traffic noise abate- } \\
\text { ment }\end{array}$ & $\begin{array}{l}\text { Reflective surface } \\
\text { needs regular main- } \\
\text { tenance and 'glare } \\
\text { effects' associated }\end{array}$ \\
\hline $\begin{array}{l}\text { Metal/composite/ } \\
\text { Polycarbonate } \\
\text { Sheets/sintered } \\
\text { metals/Plastics }\end{array}$ & $\begin{array}{l}\text { Metals, e.g. aluminium } \\
\text { with high strength to } \\
\text { width ratio }\end{array}$ & $\begin{array}{l}\text { Non transparent materi- } \\
\text { als, e.g. steel, aluminium } \\
\text { require greater efforts } \\
\text { in surface treatment to } \\
\text { soften visual impact }\end{array}$ & $\begin{array}{l}\text { Perforated metal } \\
\text { sheeting in con- } \\
\text { junction with an } \\
\text { absorptive material } \\
\text { is good for low fre- } \\
\text { quency mitigation }\end{array}$ & $\begin{array}{l}\text { Can produce glare } \\
\text { effects at certain in- } \\
\text { cident angles }\end{array}$ \\
\hline $\begin{array}{l}\text { Phase reversal type } \\
\text { barriers/Reactive } \\
\text { surface barriers }\end{array}$ & $\begin{array}{l}\text { Low frequency noise } \\
\text { control }\end{array}$ & $\begin{array}{l}\text { Technical complications, } \\
\text { practical difficult for } \\
\text { traffic noise reduction }\end{array}$ & $\begin{array}{l}\text { Specific source } \\
\text { noise mitigation }\end{array}$ & $\begin{array}{l}\text { High costs and tech- } \\
\text { nical complications }\end{array}$ \\
\hline $\begin{array}{l}\text { Active noise control } \\
\text { barriers }\end{array}$ & $\begin{array}{l}\text { Low frequency noise } \\
\text { control }\end{array}$ & $\begin{array}{l}\text { Technical complications, } \\
\text { practical difficult for } \\
\text { moving noise sources }\end{array}$ & $\begin{array}{l}\text { Specific source } \\
\text { noise mitigation }\end{array}$ & $\begin{array}{l}\text { High costs and tech- } \\
\text { nical complications }\end{array}$ \\
\hline
\end{tabular}

the advantages and limitations associated with each of them. It may be noted here that the reactive surface barriers and active noise control barriers discussed in the $S W O T$ analysis are not considered as alternatives in the present problem due to their practical limitations and high costs of installation and fabrication.

The application of the fuzzy TOPSIS method as proposed by MAHDAVI et al. (2008) is as follows:

Step 1: Choose the linguistic variables for the weight of the criteria. For the given problem, the de- cision makers use the linguistic weighting variables to assess the importance of the criteria as shown in Table 4 .

Step 2: Choose the linguistic ratings for alternatives with respect to criteria. For the given problem, the decision makers use the linguistic rating variables to evaluate the rating of alternatives with respect to each criterion as shown in Table 5 .

Step 3: Convert the linguistic ratings $\left(x_{i j}, i=1\right.$, $2, \ldots, m ; j=1,2, \ldots, n)$ for alternatives with respect 
Table 4. The importance weight of the criteria.

\begin{tabular}{|c|l|c|c|c|}
\hline & & $\mathrm{D} 1$ & $\mathrm{D} 2$ & $\mathrm{D} 3$ \\
\hline C1 & Insertion Loss & $\mathrm{H}$ & $\mathrm{VH}$ & $\mathrm{VH}$ \\
\hline C2 & Structural Integrity & $\mathrm{H}$ & $\mathrm{H}$ & $\mathrm{VH}$ \\
\hline C3 & Compatibility with Environment & $\mathrm{MH}$ & $\mathrm{H}$ & $\mathrm{M}$ \\
\hline C4 & Maintenance & $\mathrm{MH}$ & $\mathrm{MH}$ & $\mathrm{M}$ \\
\hline C5 & Safety and Durability & $\mathrm{MH}$ & $\mathrm{M}$ & $\mathrm{M}$ \\
\hline C6 & Installation & $\mathrm{H}$ & $\mathrm{MH}$ & $\mathrm{H}$ \\
\hline C7 & Corrosion resistance & $\mathrm{M}$ & $\mathrm{ML}$ & $\mathrm{ML}$ \\
\hline C8 & Economic Considerations & $\mathrm{VH}$ & $\mathrm{VH}$ & $\mathrm{VH}$ \\
\hline C9 & Ventilation, Lighting, Drainage, Vandalism & $\mathrm{ML}$ & $\mathrm{ML}$ & $\mathrm{L}$ \\
\hline
\end{tabular}

Table 5. The ratings of eleven noise barrier alternatives by decision makers with respect to nine different criteria.

\begin{tabular}{|c|c|c|c|c|c|c|}
\hline \multirow{2}{*}{\multicolumn{2}{|c|}{ Criteria }} & \multirow{2}{*}{\multicolumn{2}{|c|}{ Candidates }} & \multicolumn{3}{|c|}{ Decision Makers } \\
\hline & & & & D1 & $\begin{array}{l}\text { D2 } \\
\end{array}$ & D3 \\
\hline \multirow{10}{*}{$\mathrm{C} 1$} & \multirow{10}{*}{ Insertion Loss } & A1 & $\mathrm{T}-$ Top with absorptive top & \multicolumn{3}{|c|}{$\mathrm{VG}$} \\
\hline & & $\mathrm{A} 2$ & Y - Top with absorptive top & \multicolumn{3}{|c|}{$\bar{G}$} \\
\hline & & A3 & Jagged Top & \multicolumn{3}{|c|}{$\mathrm{F}$} \\
\hline & & $\mathrm{A} 4$ & Cylindrical Top & \multicolumn{3}{|c|}{$\mathrm{F}$} \\
\hline & & A5 & Mushroom Top & \multicolumn{3}{|c|}{$\mathrm{MG}$} \\
\hline & & $\mathrm{A} 6$ & Multiple Edge Top & \multicolumn{3}{|c|}{$\mathrm{G}$} \\
\hline & & $\mathrm{A} 7$ & Transparent & \multicolumn{3}{|c|}{ MG } \\
\hline & & A8 & Concrete & \multicolumn{3}{|c|}{$\mathrm{G}$} \\
\hline & & A9 & Reflective & \multicolumn{3}{|c|}{ F } \\
\hline & & A10 & Polycarbonate Sheets & \multicolumn{3}{|c|}{$\mathrm{F}$} \\
\hline \multirow{10}{*}{$\mathrm{C} 2$} & \multirow{10}{*}{ Structural Integrity } & A1 & $\mathrm{T}-$ Top with absorptive top & MG & MG & $G$ \\
\hline & & $\mathrm{A} 2$ & $\mathrm{Y}-$ Top with absorptive top & MG & $\mathrm{F}$ & $\mathrm{F}$ \\
\hline & & A3 & Jagged Top & $\mathrm{F}$ & $\mathrm{MG}$ & $\mathrm{F}$ \\
\hline & & $\mathrm{A} 4$ & Cylindrical Top & $\mathrm{F}$ & $\mathrm{F}$ & $\mathrm{F}$ \\
\hline & & A5 & Mushroom Top & $\mathrm{F}$ & $\mathrm{F}$ & MP \\
\hline & & A6 & Multiple Edge Top & MP & $\mathrm{F}$ & $\mathrm{F}$ \\
\hline & & A7 & Transparent & $\mathrm{MG}$ & $\mathrm{MG}$ & $\mathrm{F}$ \\
\hline & & $\mathrm{A} 8$ & Concrete & G & VG & VG \\
\hline & & A9 & Reflective & $\bar{G}$ & MG & $\mathrm{G}$ \\
\hline & & A10 & Polycarbonate Sheets & G & MG & G \\
\hline \multirow{10}{*}{ C3 } & \multirow{10}{*}{$\begin{array}{l}\text { Compatibility } \\
\text { with Environment }\end{array}$} & A1 & $\mathrm{T}-$ Top with absorptive top & $\mathrm{F}$ & $\mathrm{MG}$ & G \\
\hline & & $\mathrm{A} 2$ & $\mathrm{Y}-$ Top with absorptive top & $\mathrm{F}$ & MP & $\bar{F}$ \\
\hline & & A3 & Jagged Top & $\mathrm{F}$ & $\mathrm{F}$ & $\mathrm{MG}$ \\
\hline & & $\mathrm{A} 4$ & Cylindrical Top & $\mathrm{F}$ & $\mathrm{F}$ & $\mathrm{MG}$ \\
\hline & & A5 & Mushroom Top & $\mathrm{F}$ & $\mathrm{MG}$ & $\mathrm{MG}$ \\
\hline & & $\mathrm{A} 6$ & Multiple Edge Top & $\bar{F}$ & $\mathrm{~F}$ & $\mathrm{MG}$ \\
\hline & & A7 & Transparent & $\mathrm{MG}$ & $\mathrm{G}$ & $\mathrm{MG}$ \\
\hline & & $\mathrm{A} 8$ & Concrete & VG & VG & VG \\
\hline & & A9 & Reflective & MG & $\mathrm{MG}$ & $\bar{F}$ \\
\hline & & A10 & Polycarbonate Sheets & $\mathrm{G}$ & $\mathrm{G}$ & $\mathrm{MG}$ \\
\hline
\end{tabular}


Table 5. [Cont.]

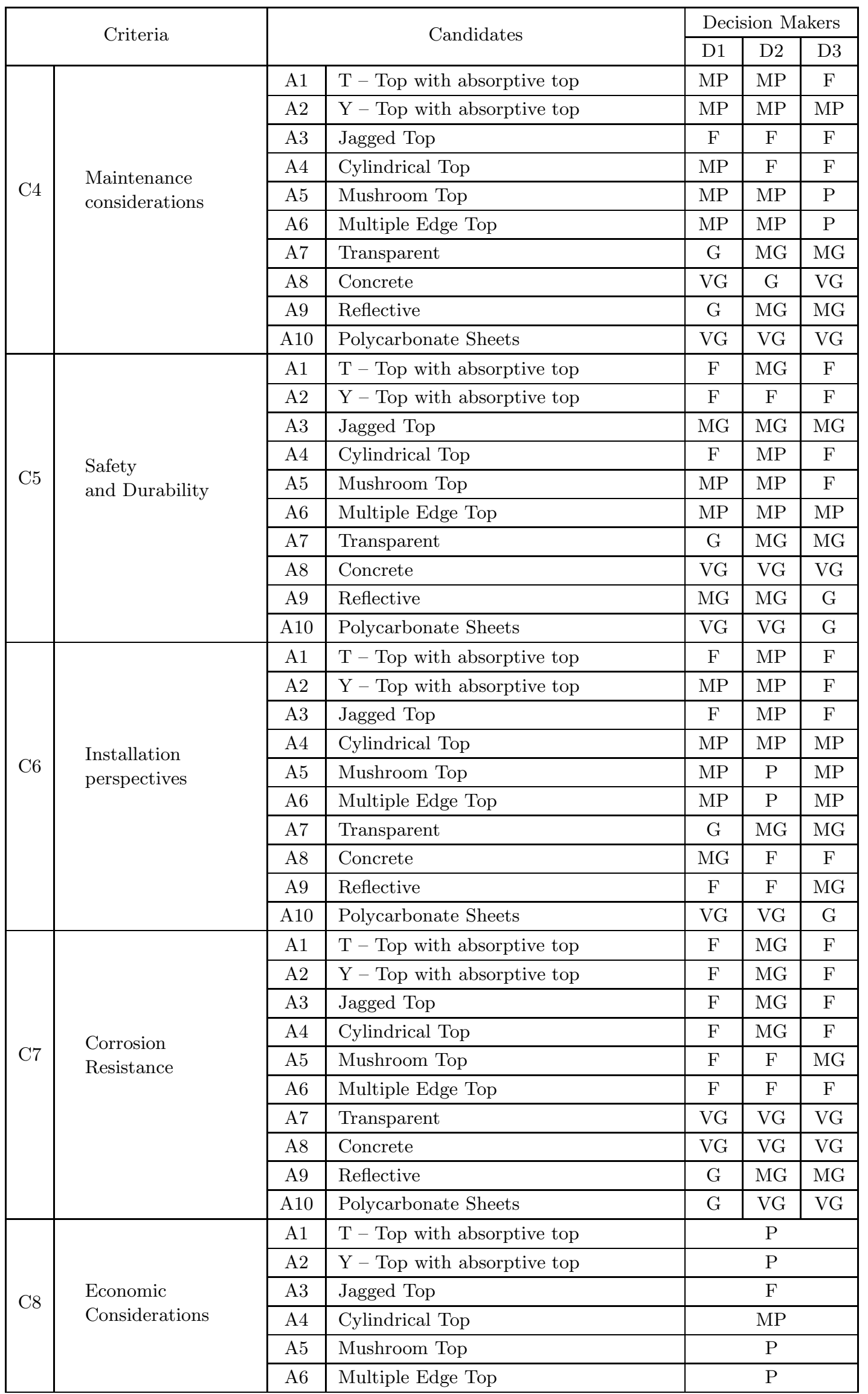


Table 5. [Cont.]

\begin{tabular}{|c|c|c|c|c|c|c|}
\hline \multirow{2}{*}{\multicolumn{2}{|c|}{ Criteria }} & \multirow{2}{*}{\multicolumn{2}{|c|}{ Candidates }} & \multicolumn{3}{|c|}{ Decision Makers } \\
\hline & & & & D1 & D2 & D3 \\
\hline \multirow{4}{*}{$\mathrm{C} 8$} & \multirow{4}{*}{$\begin{array}{l}\text { Economic } \\
\text { Considerations }\end{array}$} & A7 & Transparent & \multicolumn{3}{|c|}{ MG } \\
\hline & & $\mathrm{A} 8$ & Concrete & \multicolumn{3}{|c|}{ VP } \\
\hline & & A9 & Reflective & \multicolumn{3}{|c|}{$\mathrm{F}$} \\
\hline & & A10 & Polycarbonate Sheets & \multicolumn{3}{|c|}{ VG } \\
\hline \multirow{10}{*}{ C9 } & \multirow{10}{*}{$\begin{array}{l}\text { Ventilation, Lighting, } \\
\text { Drainage, Vandalism }\end{array}$} & $\mathrm{A} 1$ & $\mathrm{~T}-$ Top with absorptive top & $\mathrm{F}$ & $\mathrm{F}$ & $\mathrm{F}$ \\
\hline & & $\mathrm{A} 2$ & $\mathrm{Y}-$ Top with absorptive top & $\bar{F}$ & $\mathrm{~F}$ & MP \\
\hline & & A3 & Jagged Top & $\mathrm{F}$ & MP & MP \\
\hline & & A4 & Cylindrical Top & $\mathrm{F}$ & $\mathrm{F}$ & $\mathrm{MP}$ \\
\hline & & A5 & Mushroom Top & $\mathrm{F}$ & MP & MP \\
\hline & & A6 & Multiple Edge Top & $\mathrm{MP}$ & $\mathrm{MP}$ & MP \\
\hline & & A7 & Transparent & $\bar{F}$ & $\bar{F}$ & $\bar{F}$ \\
\hline & & $\mathrm{A} 8$ & Concrete & G & VG & VG \\
\hline & & A9 & Reflective & $\bar{G}$ & $\mathrm{MG}$ & $\mathrm{MG}$ \\
\hline & & A10 & Polycarbonate Sheets & $\mathrm{G}$ & VG & VG \\
\hline
\end{tabular}

to criteria and the appropriate linguistic variables $\left(w_{j}, j=1,2, \ldots, n\right)$ for the weight of the criteria into triangular fuzzy numbers using Tables 1 and 2. The fuzzy linguistic rating $\left(x_{i j}\right)$ preserves the property that the ranges of normalized triangular fuzzy numbers belong to $[0,1]$. The fuzzy $M A D M$ is thus described in the form of a matrix $\mathbf{D}$ defined by Eq. (1) and $\mathbf{W}$ is defined by Eq. (2).

$$
\begin{aligned}
& \begin{array}{c}
A_{1} \\
A_{2} \\
A_{3} \\
\cdot \\
\cdot \\
A_{m}
\end{array}\left[\begin{array}{ccccc}
x_{11} & x_{12} & x_{13} & \ldots & x_{1 n} \\
x_{21} & x_{22} & x_{23} & \ldots & x_{2 n} \\
x_{31} & x_{32} & x_{33} & \ldots & x_{3 n} \\
\cdot & \cdot & \cdot & . & \cdot \\
\cdot & \cdot & \cdot & . & \cdot \\
x_{m 1} & x_{m 2} & x_{m 3} & \ldots & x_{m n}
\end{array}\right], \\
& \mathbf{W}=\left[\begin{array}{lllll}
W_{1} & W_{2} & W_{3} & \ldots & W_{n}
\end{array}\right],
\end{aligned}
$$

where $\left(x_{i j} ; i=1,2, \ldots, m ; j=1,2, \ldots, n\right)$ and $\left(w_{j}\right.$; $j=1,2, \ldots, n)$ are linguistic triangular fuzzy numbers such that $x_{i j}=\left(a_{i j}, b_{i j}, c_{i j}\right)$ and $w_{j}=\left(w_{j 1}, w_{j 2}, w_{j 3}\right)$. Note that $w_{j}$ represents the weight of the $j$-th criteria, $C_{j}$ and $x_{i j}$ is the performance rating of the $i$-th alternative, $A_{i}$, with respect to the $j$-th criteria, $C_{j}$, evaluated by $k$ evaluators. This study applies the method of an average value to integrate the fuzzy performance score $x_{i j}$ for $k$ evaluators concerning the same evaluation criteria, that is,

$$
x_{i j}=\left(x_{i j}^{-1}+x_{i j}^{-2}+\ldots+x_{i j}^{-k}\right) / k,
$$

where $x_{i j}^{-k}$ is the rating of alternative $A_{i}$ with respect to criterion $C_{j}$ evaluated by $k$-th evaluators, and $x_{i j}^{-k}=\left(a_{i j}^{-k}, b_{i j}^{-k}, c_{i j}^{-k}\right)$. Linguistic evaluations (shown in Tables 3 and 4) are converted into triangular fuzzy numbers to construct the fuzzy decision matrix, and the fuzzy weight of each criterion given by Eq. (3) is determined.

Step 4: Construct the normalized fuzzy decision matrix. The normalized fuzzy decision matrix denoted by $\mathbf{R}$ is shown as:

$$
\mathbf{R}=\left[r_{i j}\right]_{m \times n} .
$$

If $\left(x_{i j}, i=1,2, \ldots, m, j=1,2, \ldots, n\right)$ are triangular fuzzy numbers, then the normalization process can be performed by

$$
\begin{gathered}
r_{i j}=\left(a_{i j} / c_{j}^{*}, b_{i j} / c_{j}^{*}, c_{i j} / c_{j}^{*}\right), \\
i=1,2, \ldots, m, \quad j \in B,
\end{gathered}
$$

where $B$ is the set of benefit criteria.

$$
c_{j}^{*}=\max _{i} c_{i j}, \quad j \in B
$$

Step 5: Construct the weighted normalized fuzzy decision matrix. The weighted normalized value $\mathbf{V}$ is calculated by:

$$
\mathbf{V}=\left[\begin{array}{ccccc}
v_{11} & v_{12} & v_{13} & \ldots & v_{1 n} \\
v_{21} & v_{22} & v_{23} & \ldots & v_{2 n} \\
v_{31} & v_{32} & v_{33} & \ldots & v_{3 n} \\
\vdots & \vdots & \vdots & \ddots & \vdots \\
v_{m 1} & v_{m 2} & v_{m 3} & \ldots & v_{m n}
\end{array}\right]
$$




$$
\mathbf{V}=\left[\begin{array}{cccccc}
w_{1} r_{11} & w_{2} r_{12} & \ldots & w_{j} r_{1 j} & \ldots & w_{n} r_{1 n} \\
w_{1} r_{21} & w_{2} r_{22} & \ldots & w_{j} r_{2 j} & \ldots & w_{n} r_{2 n} \\
\vdots & \vdots & \ddots & \vdots & \ddots & \vdots \\
w_{1} r_{i 1} & w_{2} r_{i 2} & \ldots & w_{j} r_{i j} & \ldots & w_{n} r_{i n} \\
\vdots & \vdots & \ddots & \vdots & \ddots & \vdots \\
w_{1} r_{m 1} & w_{2} r_{m 2} & \ldots & w_{j} r_{m j} & \ldots & w_{n} r_{m n}
\end{array}\right]
$$

Step 6: Identify the set of positive ideal $\left(A^{*}\right)$ and negative ideal $\left(A^{-}\right)$solutions. For the order of selecting the fuzzy positive ideal solution $\left(F P I S, A^{*}\right)$ and the fuzzy negative ideal solution $\left(F N I S, A^{-}\right)$, it is thus utilized as (MAHDAVI et al., 2008):

$$
\begin{aligned}
F P I S & =A^{*}=\left(v_{1}^{*}, v_{2}^{*}, v_{3}^{*}, \ldots, v_{n}^{*}\right) \\
& =\left\{\left(\max _{i} v_{i j} / i=1,2, \ldots, m\right), j=1,2, \ldots, n\right\}, \\
F N I S & =A^{-}=\left(v_{1}^{-}, v_{2}^{-}, v_{3}^{-}, \ldots, v_{n}^{-}\right) \\
& =\left\{\left(\min _{i} v_{i j} / i=1,2, \ldots, m\right), j=1,2, \ldots, n\right\} .
\end{aligned}
$$

The situations of FPIS and FNIS, as well as the corresponding triangular fuzzy numbers of those situations are determined.

Step 7: The similarity degree of each alternative from $A^{*}$ and $A^{-}$as $S^{*}$ and $S^{-}$, can be calculated by using the following equation (MAHDAVI et al., 2008):

$$
S(a, b)=\frac{1}{1+D_{2,1 / 2}(a, b)},
$$

where $D_{p, q}$ is the distance, indexed by the parameters $1<p<\infty$ and $0<q<1$, between two fuzzy numbers $a$ and $b$, and is a non-negative function as described next.

For the triangular fuzzy numbers $a=\left(a_{1}, a_{2}, a_{3}\right)$ and $b=\left(b_{1}, b_{2}, b_{3}\right)$ the above distance with $p=2$ and $q=1 / 2$ is calculated as:

$$
D_{2,1 / 2}(a, b)=\sqrt{\frac{1}{6}[x+y]}
$$

where

$$
\begin{aligned}
& x=\sum_{i=1}^{3}\left(b_{i}-a_{i}\right)^{2}+\left(b_{2}-a_{2}\right)^{2}, \\
& y=\sum_{i \in\{1,2\}}\left(b_{i}-a_{i}\right)\left(b_{i+1}-a_{i+1}\right) .
\end{aligned}
$$

Step 8: Calculate similarities to the ideal solution. This step solves the similarities to an ideal solution by the following equation:

$$
C C_{i}=\frac{S_{i}^{-}}{S_{i}^{-}+S_{i}^{*}}
$$

Step 9: Rank the preference order. Choose an alternative with minimum $C C_{i}$ or rank the alternatives according to $C C_{i}$ in the ascending order. Figure 2 summarizes the procedure of application of the fuzzy TOPSIS methodology (MAHDAVi et al., 2008) in a flow chart.

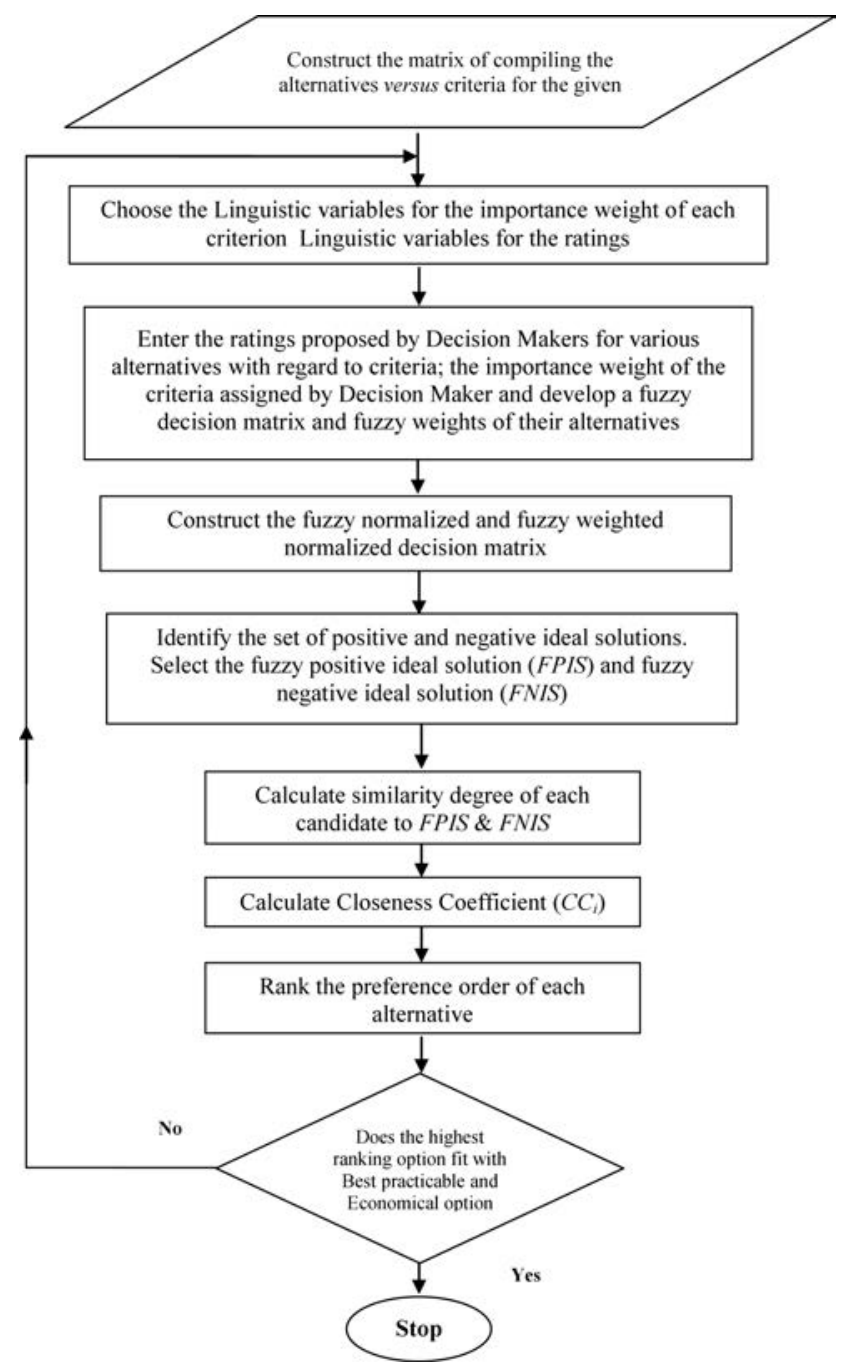

Fig. 2. Flow chart of the Fuzzy TOPSIS approach.

\section{Application of the TOPSIS approach}

\subsection{Problem formulation}

The application of the fuzzy TOPSIS approach demonstrated by MAHDAVI et al., 2008 and discussed previously is thus utilized for selection of the optimal road traffic noise abatement strategy. The hierarchical structure of the problem is shown in Fig. 3. The various benefit criteria considered for the problem are summarized as:

- Insertion Loss (C1),

- Structural Integrity (C2),

- Compatibility with Environment (C3), 


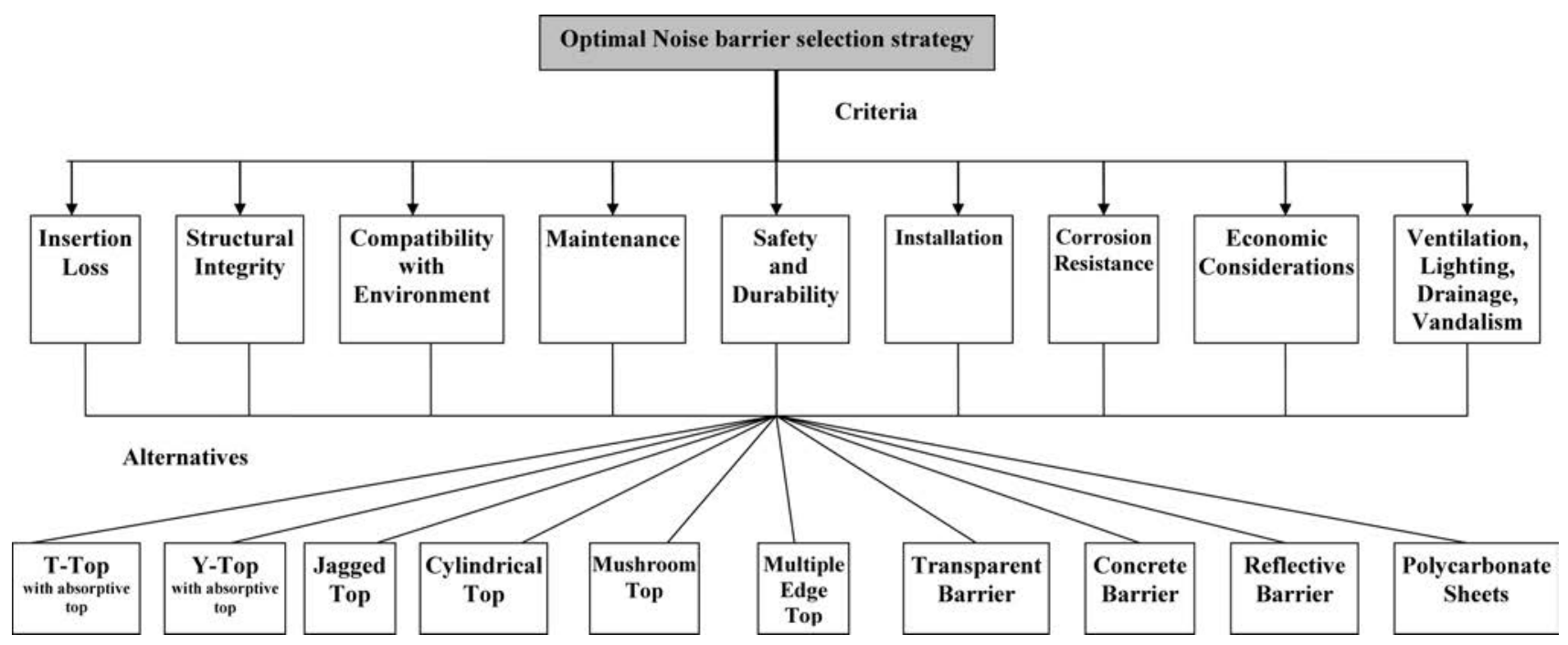

Fig. 3. Various alternatives and criteria considered for selecting the optimal noise barrier for road traffic noise abatement.

- Maintenance (C4),

- Safety and Durability (C5),

- Installation (C6),

- Corrosion Resistance (C7),

- Economic Considerations (C8), and

- Ventilation, Lighting, Drainage, Vandalism (C9)

The various alternatives, i.e., types of noise barriers considered for road traffic noise abatement are:

- T-top with absorptive top,

- Y-top with absorptive top,

- Jagged top,

- Mushroom top,

- Cylindrical top,

- Multiple edges,

- Reflective,

- Transparent,

- Concrete,

- Polycarbonate sheet.

Table 3 shows the Strength, Weaknesses, Opportunities, and Threats (SWOT) for various types of noise barriers options available, which can help a decision maker to identify the pros and cons associated with each alternative while awarding the linguistic ratings. The fuzzy TOPSIS approach is utilized to select the best alternative amongst A1 to A10 satisfying the benefit criteria $\mathrm{C} 1$ to $\mathrm{C} 9$. Three experienced decision makers: D1, D2, and D3, gave their opinions in terms of linguistic variables. The experienced decision makers use the linguistic weighting variables for ascertaining the importance of the eight criteria as shown in Table 4. Then linguistic rating variables for evaluating the rating of the alternatives with respect to each criteria was assigned by the three decision makers as shown in Table 5 . The linguistic variables were converted into triangular fuzzy numbers listed in Tables 1 and 2. It may be noted here that for the criteria "insertion loss" and "economic considerations", a relative comparison was done by the decision makers based on the insertion loss provided by the ten alternatives in $\mathrm{dB}(\mathrm{A})$ and costs incurred in Rupees $/ \mathrm{m}^{2}$. As these two factors are based on actual calculations, so Table 5 incorporates the decisions D1, D2, and D3 as same for these criteria. Thus, for T-top barriers with the absorptive top of the highest insertion loss, a linguistic variable of Very Good (VG) is assigned, which is transformed into equivalent triangular fuzzy numbers listed in Table 2. The polycarbonate sheet option, reflective barriers were assigned a Fair rating. While comparing the costs, the concrete barriers have the highest costs incurred in Rupees $/ \mathrm{m}^{2}$ and thus it is assigned a Very Poor (VP) rating, as minimal cost was the preferred alternative. However, the polycarbonate sheets have the minimum costs incurred in Rupees $/ \mathrm{m}^{2}$ and thus it was assigned a Very Good (VG) rating. A Matlab code, TOPSIS.m was developed for doing all these computations in minimum time intervals.

\subsection{Results and discussion}

Table 5 exhibits the ratings of seven alternatives by decision makers under all criteria. The fuzzy decision matrix and fuzzy weights of their alternatives are determined as shown in Table 6. Consequently, a fuzzy normalized decision matrix is developed as shown in Table 7 . The weighted normalized fuzzy decision matrix is developed as shown in Table 8. Table 9 shows the FPIS and FNIS values determined using step 6 described in Sec. 2.

The similarity degree of each alternative from FPIS is given in Table 10, while that from FNIS is in Table 11. Finally, the closeness coefficient of each alternative is calculated in Table 12 . 


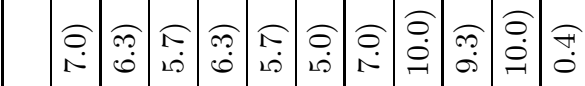

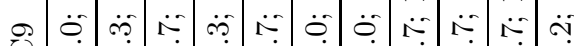

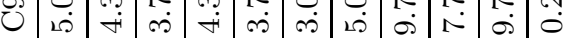

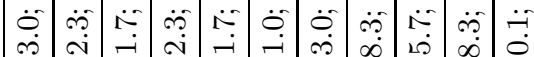

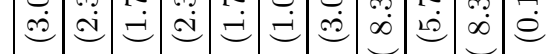

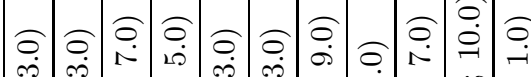

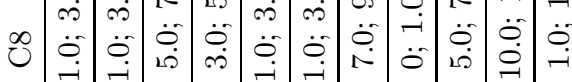

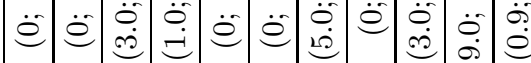

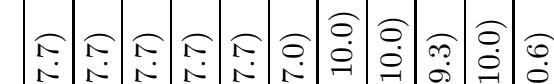

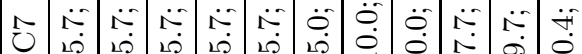

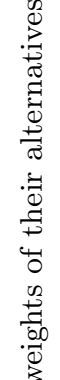

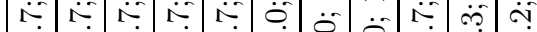

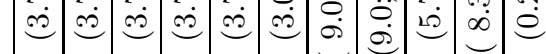

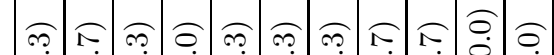

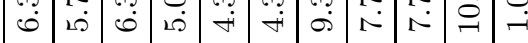

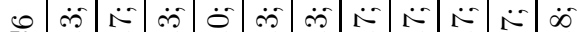

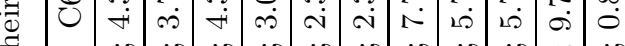

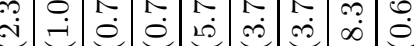
西 胥

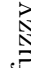
$\stackrel{乛}{\Xi}$ สี 党 . 胥 T 次

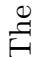
F 0

$\stackrel{\frac{\pi}{4}}{\frac{0}{4}}$

ச

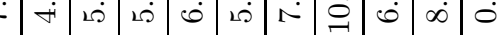

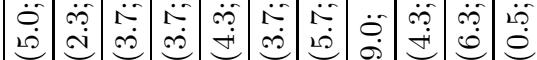

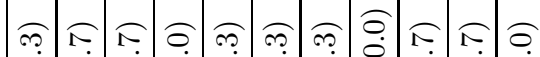

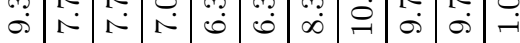

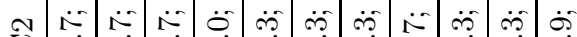

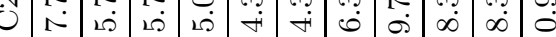

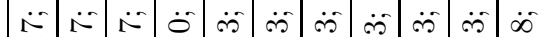
एक

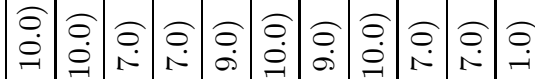

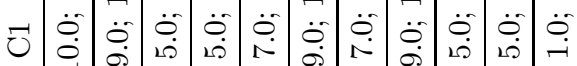
O

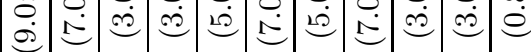

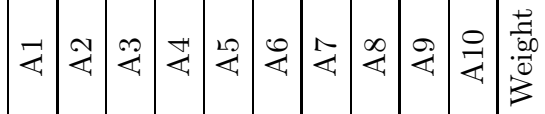

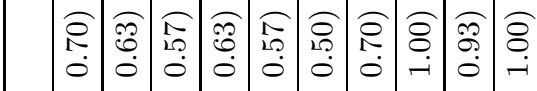

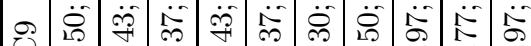
$\begin{array}{lllllllllllllllll}0 & 0 & 0 & 0 & 0 & 0 & 0 & 0 & 0 & 0 & 0\end{array}$

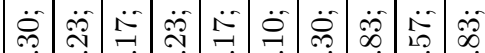

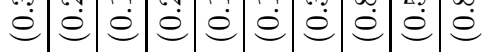
Әे

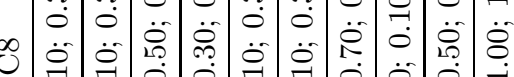
$\because \begin{array}{llllllllll}0 & 0 & 0 & 7 & \ddots & 0 & 0 & 0 & 0 \\ 0 & 0 & 0 & 0 & 0 & \cdots & 0 & 0 & 0\end{array}$

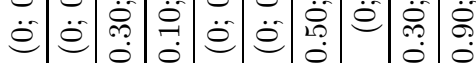

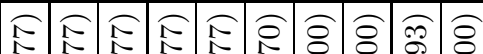

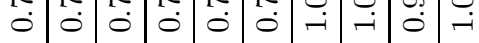

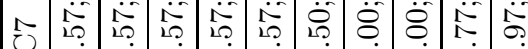
$\begin{array}{llllllllll}0 & 0 & 0 & 0 & 0 & 0 & - & -i & 0 & 0\end{array}$

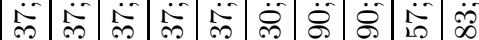

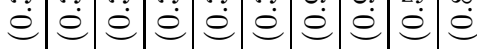

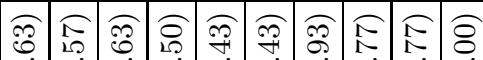

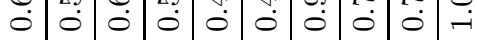

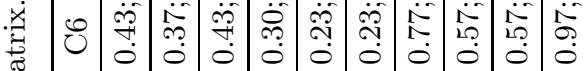
范 .

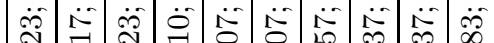

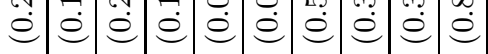

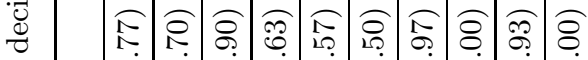

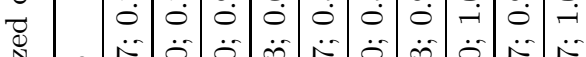

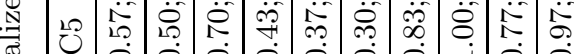
:

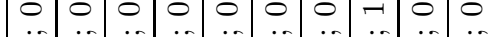

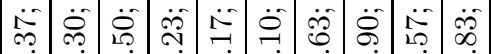

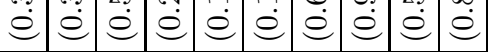

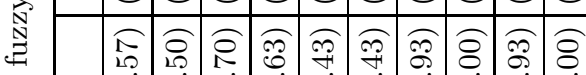

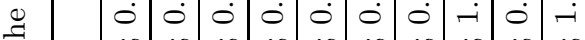
স4

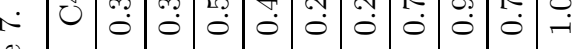

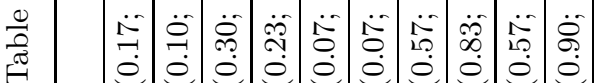

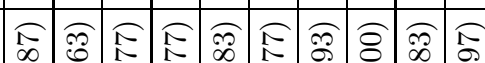

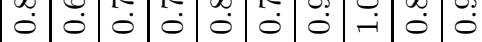

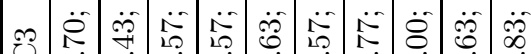

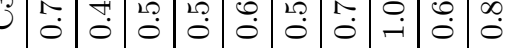

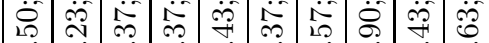

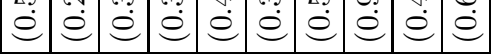

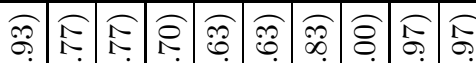

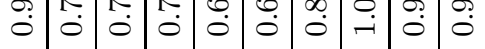

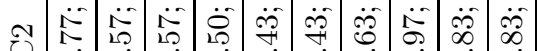

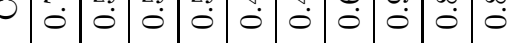
灾

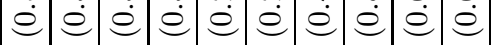

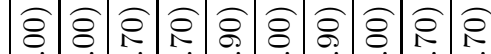

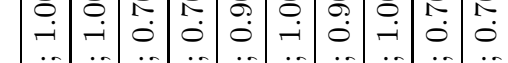

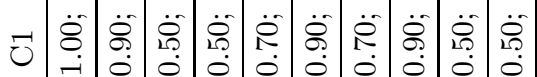

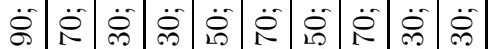

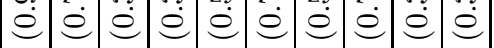

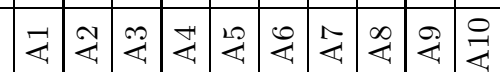


|क्के

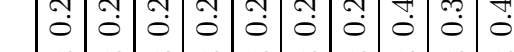

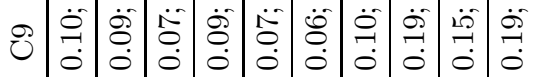

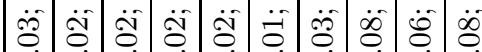

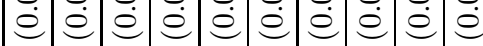

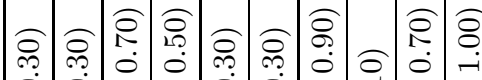

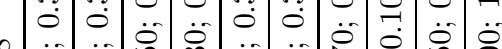
我

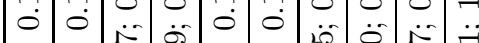

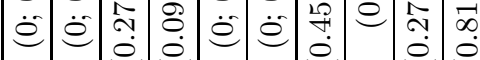
ชิ

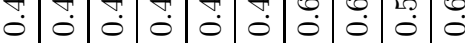

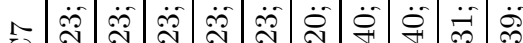

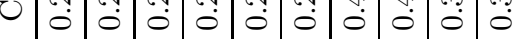

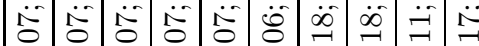

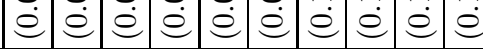

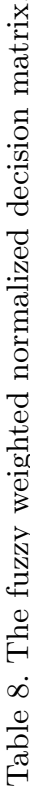

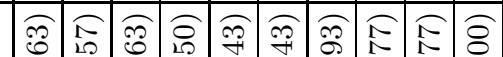

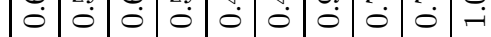

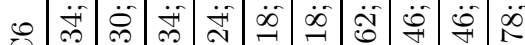

$\begin{array}{llllllllll}0 & 0 & 0 & 0 & 0 & 0 & 0 & 0 & 0 & 0\end{array}$

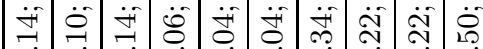

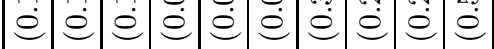
总

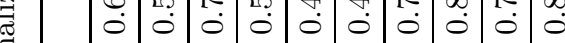

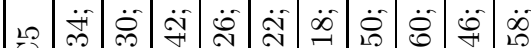
$\begin{array}{llllllllllllllll}0 & 0 & 0 & 0 & 0 & 0 & 0 & 0 & 0 & 0 & 0 \\ 0\end{array}$ च

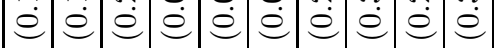
ชิ

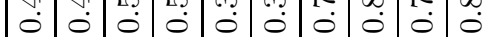

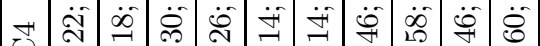
$\ddot{0}$ ப்

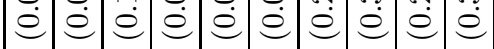
全

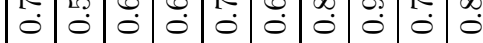
円 $\begin{array}{cccccccccc}0 & 0 & 0 & 0 & 0 & 0 & 0 & 0 & 0 & 0\end{array}$ 

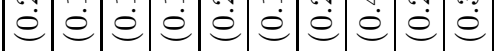

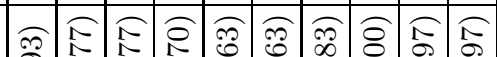

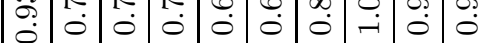

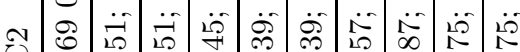

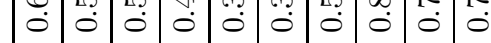

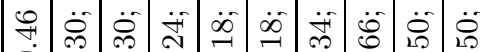

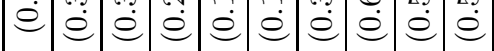

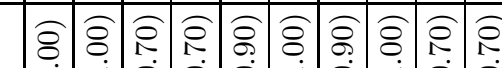

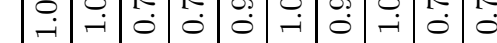
ப

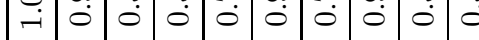
నิ

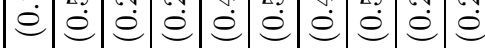

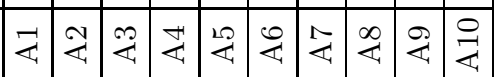

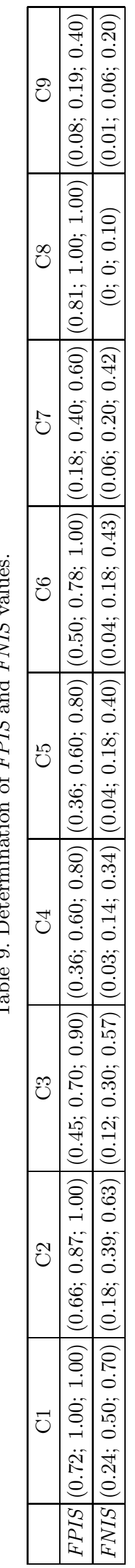

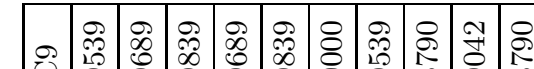

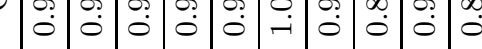

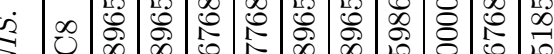
$\begin{array}{lllllllllll} & 0 & 0 & \dot{0} & 0 & 0 & 0 & 0 & - & \dot{0} & 0 \\ 0\end{array}$

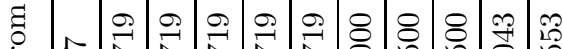
$\exists$ U

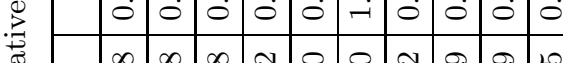

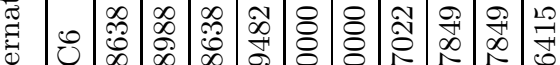

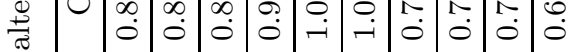
卷

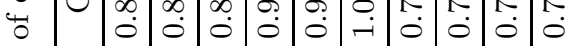

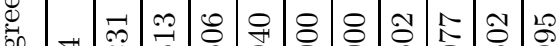
¿্ర

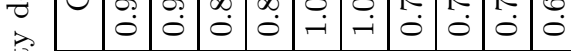

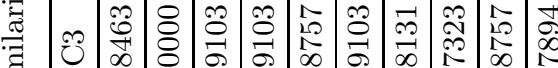

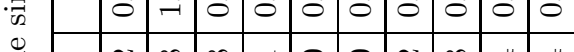

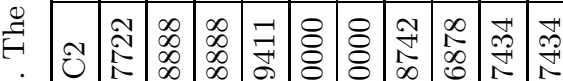

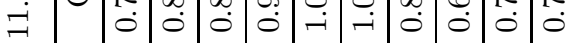

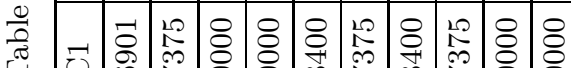

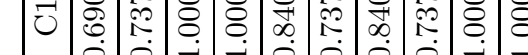

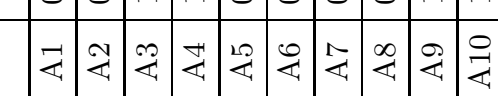

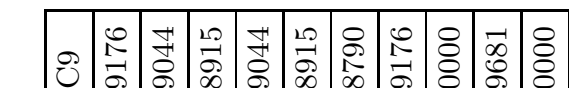

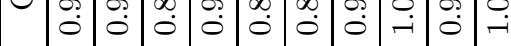

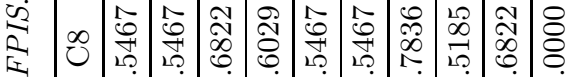

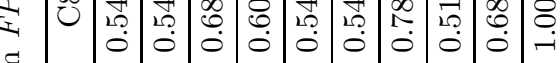

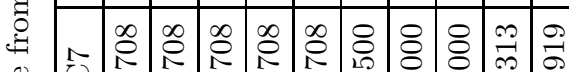

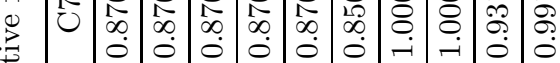
医

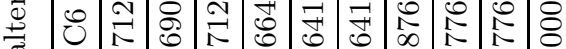

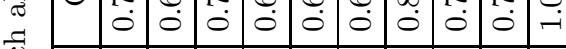
牙 ப

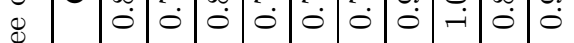
总 J゙

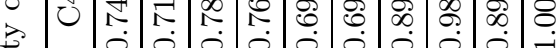

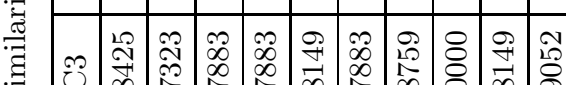

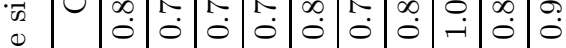
舀

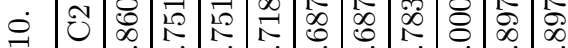
$\because \quad$\begin{tabular}{lllllllllll}
0 & 0 & 0 & 0 & 0 & 0 & 0 & 0 & - & 0 & 0 \\
\hline
\end{tabular} त्व J

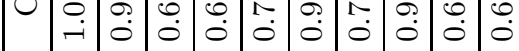

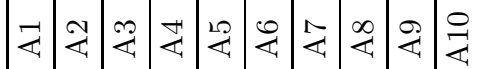


Table 12. Ranking of various alternatives for optimal noise barrier selection.

\begin{tabular}{|c|c|c|c|c|}
\hline & $S_{i}^{*}$ & $S_{i}^{-}$ & $C C_{i}$ & Rank \\
\hline $\mathrm{A} 1$ & 7.3063 & 7.7758 & 0.5156 & $\mathrm{~V}$ \\
\hline $\mathrm{A} 2$ & 6.9105 & 8.2148 & 0.5431 & $\mathrm{VII}$ \\
\hline $\mathrm{A} 3$ & 7.0420 & 7.9598 & 0.5306 & $\mathrm{VI}$ \\
\hline $\mathrm{A} 4$ & 6.7623 & 8.3381 & 0.5522 & $\mathrm{VIII}$ \\
\hline $\mathrm{A} 5$ & 6.6855 & 8.5265 & 0.5605 & $\mathrm{X}$ \\
\hline $\mathrm{A} 6$ & 6.7196 & 8.5442 & 0.5598 & $\mathrm{IX}$ \\
\hline $\mathrm{A} 7$ & 7.8412 & 7.1278 & 0.4762 & $\mathrm{III}$ \\
\hline $\mathrm{A} 8$ & 8.1834 & 7.0981 & 0.4645 & $\mathrm{II}$ \\
\hline $\mathrm{A} 9$ & 7.5463 & 7.4333 & 0.4962 & $\mathrm{IV}$ \\
\hline $\mathrm{A} 10$ & 8.4656 & 6.8542 & 0.4474 & $\mathrm{I}$ \\
\hline
\end{tabular}

It can be thus observed that the ranking order of eleven alternatives is A10, A8, A7, A9, A1, A3, A2, A4, A6, and A5. The best optimal alternative is A10, which is polycarbonate sheets followed by concrete barriers, transparent barriers, reflective barrier, T-top with absorptive top, Jagged top, Y-top with absorptive top, cylindrical, multiple edges barrier, and mushroom top barriers.

It may be noted here that the present order cannot be generalized to every site and situation and thus, the selection of the optimal alternative may differ from one site to another. Also, the expert opinion may differ on each and every aspect pertaining to the site specific conditions, etc., as the effectiveness of a noise barrier depends upon its geometry; acoustic characteristics such as sound reflection, diffusion of surface exposed to noise, airborne sound insulation; installation factors; deterioration with time; site geometry; ground profile; site acoustic characteristics; ground impedance, and meteorological conditions (GARAI et al., 2000). However, the present work serves as an illustrative example that can be easily applied with no computational complexities inviting the opinion of any number of experts (fuzzy numbers will change) to formulate an effective strategy for selection and installation of a noise barrier considering all these alternatives with regard to criteria considered. It may be noted that in the present study, the multiple edges top barrier is selected as the least priority, which may not be applicable for every site or source noise mitigation. The application of multiple edges top barriers or the so called profiled noise barriers having a better acoustical performance than conventional concrete structures can be very effective for specific applications wherein a single source has to be screened. The noise barrier designed for Delhi Metro Rail Corporation (DMRC), New Delhi, India consisting of half $\mathrm{Y}$ shaped structure that includes a $2 \mathrm{~mm}$ thick aluminium alloy as the back plate, $1 \mathrm{~mm}$ thick aluminium alloy sheet (30\% open) as facing surface, $50 \mathrm{~mm}$ thick glasswool of density $40 \mathrm{~kg} / \mathrm{m}^{3}$ wrapped in tissue bags and polythene cover, and the whole assembly fixed in a GI framework serves as an illustration of specific source noise mitigation (MOHANAN et al., 2001). The use of the TOPSIS approach can thus be very helpful for the town planners and development authorities for selecting the best practicable option, considering all the pros and cons, as the long term stability of the barrier and compatibility with the local environment are equally important as the acoustical considerations are, especially for the road traffic noise abatement and control (GARG et al., 2015a; 2015b).

\section{Conclusions}

The paper presents an application of TOPSIS method with fuzzy data to determine the most preferable choice amongst all the possible types of noise barriers available for traffic noise abatement. The work utilizes the fuzzy TOPSIS model proposed by MAHDAVI et al. 2008 in selecting the best alternative with regard to various criteria considered. A SWOT analysis of various types of noise barrier options is presented. Thus, a case study of eleven noise barrier alternatives with respect to nine different criteria is presented whereby three decision makers have assigned the linguistic variables for rating these alternatives. Consequently, a fuzzy decision matrix is developed obtaining the FPIS and FNIS values. The closeness coefficient of each alternative is finally calculated so as to determine the ranking order of all alternatives. The proposed methodology is simple and easy to apply and thus finds its great applicability in various decision making problems. It is envisaged that the fuzzy TOPSIS approach can be efficiently utilized by town planners, architects, and development authorities in selection of Best Practicable and Economical Option (BPEO). The present approach is flexible in handling a large number of alternatives for several criteria, which makes it indispensable to be considered in solution of such problems. Thus, the approach is quite flexible for solving problems related to selection of appropriate material for only one type of barriers also subject to the criteria listed in the paper. It may be noted that linguistic variables assigned for each of the noise barrier alternatives versus criteria considered cannot be generalized to every situation and thus may change according to the site specific conditions and judgment of a decision maker. However, the methodology demonstrated can be widely applied to any site or source specific noise mitigation for decision making process to select and install optimal noise barriers. Future work shall focus on the comparison of the results sought with the above methodology with that to the use of other decision making problems. 


\section{Acknowledgments}

The authors are very thankful to the anonymous reviewers for their helpful comments and suggestions. They are also thankful to the retired colleagues, Mr. Omkar Sharma, Dr. V. Mohanan, Dr. Ashok Kumar, Dr. S.P. Singal, Late Dr. T.K. Saxena and Dr. P.K. Saini, Associate Professor, NIT Kurukshetra, India for their suggestions and guidance in the present study. The authors thank Director, NPL and Head, ALSIM, NPL for their constant encouragement and support. One of the authors thanks Senior Director and Director, Amity School of Engg. and Technology, Delhi for their support of the research work. The authors shall appreciate any corrections, suggestions, or updates of information.

\section{References}

1. Behzadian M., Otaghsara S.K., Yazdani M., IGNATius J. (2012), A state-of the-art survey of TOPSIS applications, Expert Systems with Applications, 39, 13051-13069.

2. Baulac M., Defrance J., Jean P. (2008), Optimization with genetic algorithm of acoustical performance of T-shaped noise barriers with a reactive top surface, Applied Acoustics, 69, 4, 332-342.

3. Cheng W.F., NG C.F. (2001), The acoustic performance of an inclined barrier for high-rise residents, J. Sound and Vibration, 242, 2, 295-308.

4. Cianfrini C., Corcione M., Fontana L. (2007), Experimental verification of the acoustic performance of diffuse roadside noise barriers, Applied Acoustics, 68, $1357-1372$.

5. Crombie D.H., Hothersall D.C., ChandlerWiLde S.N. (1995), Multiple-edge noise barriers, Applied Acoustics, 44, 4, 353-367.

6. Chiun-Ming Liu, Mei-Yu Ji, Wen-Chieh Chuang (2013), Fuzzy TOPSIS for Multiresponse Quality Problems in Wafer Fabrication Processes, Advances in Fuzzy Systems Volume, Article ID 496158, 6 pages.

7. Egan C.A., Chilekwa V., Oldham D.J. (2006), An investigation of the use of the top edge treatments to enhance the performance of a noise barrier using boundary element method, 13th International Congress on Sound and Vibration, Vienna, Austria, 1-6th July.

8. Daigle G.A. (1999), Report by the International Institute of Noise Control Engineering Working Party on Technical Assessment of the Effectiveness of Noise walls, I-INCE Publication 99-1, Noise/News International, 137-161.

9. Ding J.F. (2011), An integrated Fuzzy TOPSIS method for ranking alternatives and its application, Journal of Marine Science and Technology, 19, 4, 341-352.

10. Fahy F.J., Ramble D.G., Walker J.G., SugiuRA M. (1995), Development of a novel modular form of sound absorbent facing for traffic noise barrier, Applied Acoustics, 44, 1, 39-51.
11. Fujiwara K., Hothersall D.C., Kim Chul-hwan, (1998), Noise barriers with reactive surfaces, Applied Acoustics, 53, 4, 255-272.

12. Garg N., Kumar A., Maji S. (2013), Significance and implications of airborne sound insulation criteria in building elements for traffic noise abatement, Applied Acoustics, 74, 1429-1435.

13. Garg N., Sharma O., Mohanan V., Maji S. (2012), Passive noise control measures for traffic noise abatement in Delhi, India, Journal of Scientific and Industrial Research, 71, 226-234.

14. Garg N., Kumar A., Saini P.K., Maji S. (2015a), A retrospective view of ambient noise standards in India: Status and proposed revision, Noise Control Engg. Journal, 63, 3, May-June 20, 1-14.

15. Garg N., Mangal S.K., Saini P.K., Dhiman P., MAJI S. (2015b), Comparison of ANN and analytical models in traffic noise modelling and predictions, Journal of Acoustic Australia, 43, 179-189.

16. Guidelines on design of noise barriers, SAR, 2nd issue (Environmental Protection Department, Highways Department, Govt. of Hongkong), Jan 2003.

17. Garai M., Guidorzi P. (2000), European methodology for testing the airborne sound insulation characteristics of noise barriers in situ: Experimental verification and comparison with laboratory data, J. of Acoustical society of America, 108, 3, 1054-1067.

18. Ho S.S.T., Busch-Vishniac I.J., Blackstock D.T. (1997), Noise reduction by a barrier having a random edge profile, J. of Acoustical society of America, 101, 2669-2676.

19. Highway Traffic Noise, federal Highway administration, US Deptt. of Transportation, http://www.fhwa. dot.gov/environment/noise/noise_barriers/design_construction/design/design04.cfm.

20. Hothersall D.C., Crombie D.H., Chandler-WilDE S.N. (1991), The performance of T-profile and associated noise barriers, Applied Acoustics, 32, 4, 269287.

21. Hwang C.L., Yoon. K. (1981), Multiple Attribute Decision Making, Springer-Verlag, Berlin.

22. Hung C.C., Chen L.H. (2009), A Fuzzy TOPSIS Decision Making Model with Entropy Weight under Intuitionistic Fuzzy Environment, Proceedings of the International Multi Conference of Engineers and Computer Scientists 2009, Vol. I, IMECS 2009, March 1820, 2009, Hong Kong.

23. Ishizuka T., Fujiwara K. (2004), Performance of noise barriers with various edge shapes and acoustic conditions, Applied Acoustics, 65, 2, 125-141.

24. Monazzam M.R., Ford S.M.B. (2011), Performance of passive and reactive profiled median barriers in traffic noise reduction, Journal of Applied Physics and Engineering (Zhejiang Univ. Sci A), 12, 1, 78-86.

25. Monazzam M.R., Naderzadeh M., Nassiri P., FARD S.M.B. (2010), Performance of environmental T-shape noise barriers covered with primitive root diffusers, Archieves of Acoustics, 35, 4, 565-578. 
26. May D.N., Osman M.M. (1980), Performance of sound absorptive, reflective and T-profile noise barriers in Toronto, J. Sound and Vibration, 71, 1, 65-71.

27. Mahdavi I., Mahdavi-Amiri N., Heidarzade A., NOURIFAR R. (2008), Designing a model of fuzzy TOPSIS in multiple criteria decision making, Applied Mathematics and Computation, 206, 2, 607-617.

28. Mohanan V., Sharma O. (2001), Acoustical design of a noise barrier for an elevated rail corridor, J. Acoust. Soc. of India, 28, 95-100.

29. Ouis D. (2003), Noise diffraction by a hard wedgeshaped barrier, J. Sound and Vibration, 262, 2, 347364 .

30. Olson D.L. (2004), Comparison of weights in TOPSIS models, Mathematical and Computer Modelling, 40, 721-727.

31. Prascevic Z., Prascevic N. (2013), One modification of fuzzy TOPSIS method, Journal of Modelling in Management, 8, 81-102.

32. RiBEIRo R.A. (1996), Fuzzy multiple attribute decision making: a review and new preference elicitation techniques, Fuzzy Sets and Systems, 78, 2, 155-181.

33. Shao W., Lee H.P., Lim S.P. (2001), Performance of noise barriers with random edge profiles, Applied Acoustics, 62, 10, 1157-1170.

34. Shin H.-S., Lin W.Y., Lee E.S. (2001), Group decision making for TOPSIS, [in:] Joint 9th IFSA World Congress and 20th NAFIPS International Conference,
IFSA/NAFIPS 2001, 25-28 July, Vancouver, Canada, 2001, pp. 2712-2717.

35. Shin H.-S., Shyur H.J., Lee E.S. (2007), An extension of TOPSIS for group decision making, Mathematics and Computer Modelling, 45, 801-813.

36. Shahanaghi K., Yazdian S.A. (1999), Vendor selection using a new Fuzzy group TOPSIS approach, J. of Uncertain Systems, 3, 221-231.

37. Velasquez M., Hester P.T. (2013), An Analysis of Multi-Criteria Decision Making Methods, International Journal of Operations Research, 10, 2, 56-66.

38. Watts G.R., Morgan P.A., Surgand M. (2004), Assessment of diffraction efficiency of novel barrier profiles using a MLS-based approach, J. Sound and Vibration, 274, 3-5, 669-683.

39. WATSON D. (2006), Evaluation of benefits and opportunities for innovative noise barrier designs, Final report 572, Arizona Department of Transportation.

40. Watts G.R. (2002), Barrier designs to reduce road traffic noise, Proceedings of the Institution of Civil Engineers, Transport, 153, 2, 79-86.

41. Watts G.R. (1996), Acoustic performance of parallel traffic noise barriers, Applied Acoustics, 47, 2, 95-119.

42. Yoon K.P., Hwang C.L. (1995), Multiple Attribute Decision Making: An Introduction, Sage Pub., Thousand Oaks, CA.

43. YEH C.-H. (2002), A problem-based selection of multi-attribute decision-making methods, International Transactions in Operational Research, 9, 169-181. 